\title{
La Corrupción como Resultado de la Desorganización Social
}

\author{
Juan Luis Posse Fregoso \\ Facultad de Ciencias Políticas y Administración Pública-UAEM
}

\begin{abstract}
Resumen: El presente artículo se enfoca al análisis del fenómeno de la corrupción como resultado de un complejo proceso que implica la conjugación de múltiples factores para manifestarse como un hecho integral en el contexto social. Estos factores se analizan por separado para establecer las causas que provocan la aparición de la corrupción en cada nivel y a su vez establece sus puntos de convergencia. La aceptación de la multicausalidad de los fenómenos sociales es consecuencia de la innegable interrelación existente en el entorno de la vida humana de los factores: sociales, políticos, psicológicos y administrativos. En este sentido, pretendo lejos de parcializar teóricamente la visión general del problema, descubrir las causas comunes que se reflejan en la desorganización de la sociedad y que son las que realmente desencadenan la aparición del fenómeno en estudio.

Abstract: The present article was focused to the analysis of the phenomenon of the corruption as result of a complex process that implicated the conjugation of multiple factors to be manifested as a done integral in the social context. These factors analyze separately with the object of establishing the specific causes that provoke the apparition of the corruption in every level and to the time establishes the points of convergence. The acceptance of the many causes of the social phenomena is consequence of the undeniable relations existing in the context of the human life of the factors: social, political, psychological and administrative. In this sense, purport far of fragment theoristically the general vision of the problem, to discover the similar causes that reflect the social desorganization and that are the really unchain the apparition of the phenomenon in study.
\end{abstract}

\section{Introducción}

Planteamiento

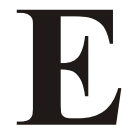

n las últimas décadas en México, hemos sido testigos circunstanciales de verdaderos escándalos relacionados con actos de corrupción, protagonizados por funcionarios, ex-funcionarios y prominentes miembros de la sociedad civil. La corrupción se ha convertido en el principal problema social de nuestro país.

La indignación manifiesta de la población frente a estas corruptelas, aunada a la profunda crisis económica que ha impactado principalmente a las clases sociales marginadas del proceso de 
crecimiento económico, ha profundizado la brecha entre pueblo y gobierno, colocando a la nación al borde de una ruptura en la armonía social.

Aunque el gobierno ha tratado de implementar algunas medidas paliativas para lograr la disminución de actos de corrupción dentro de sus estructuras, éstas han carecido de la consistencia necesaria para aplicarlas en el plano de la realidad, debido a su falta de interés por definir las raíces del problema, ya que como se verá más adelante es el mismo Estado quien promueve esta conducta desviada como forma de vida, en tanto que favorece la preservación de los intereses del grupo político que detenta el poder. Un esfuerzo serio para tratar de disminuir la frecuencia con la que aparece este fenómeno debe encaminarse al diagnóstico de causas y no limitarse a actuar únicamente sobre los efectos, pues esto equivale a tratar de curar una enfermedad con analgésicos para eliminar los síntomas, pero sin atacar al agente patógeno.

A partir de ello, fue palmaria la necesidad de profundizar la investigación documental en la materia, encontrando que el problema de la corrupción es abordado de manera muy general dentro del estudio de otros fenómenos como la violencia, los delitos y en general otro tipo de conductas desviadas, por especialistas con muy variada formación y enfoques diversos. De ahí que, desde mi muy particular óptica, haya decidido analizarlo de manera integral para tratar de sistematizar y explicar todos los factores que se encontraban relacionados con este concepto.

La teoría del conocimiento, la pragmática y la moral constituyen en última instancia la esencia misma de la filosofía del hombre. El hecho es que aunque cada ciencia o disciplina posea sus propias leyes, conceptos y métodos que conducen a conclusiones distintas por su nivel de abstracción, su objeto de estudio es único e indivisible: el hombre, y por lo mismo, todas pueden considerarse dentro de la filosofía del humanismo, a final de cuentas.

La corrupción se nos presenta así como un complejo sincretismo en el cual se amalgaman diversos factores que actúan de manera independiente, pero que a la vez convergen en el sujeto de estudio que es el hombre concebido como una unidad bio-psico-social.

En todo caso, lo importante es la concientización de que para resolver este complejo problema es la sociedad quien debe determinar 
los principales factores que desencadenan la aparición de este fenómeno como un hecho recurrente, para estar en posibilidad de sugerir alternativas viables que contemplen una solución integral a este problema. Recordemos que si la investigación es ante todo encuentro con la verdad, este encuentro deberá realizarse mediante la suma de las partes y esta suma sólo puede realizarse desembocando al río totalizador del conocimiento general.

\section{Propósitos}

Identificar en la realidad los diversos factores que propician la aparición de la corrupción como un fenómeno social objetivo, a fin de establecer su etiología.

Confrontar los hechos derivados de la observación directa con la investigación documental y experiencia, a fin de validar las hipótesis de la investigación con un respaldo teórico suficiente.

\section{Definición}

Según María Moliner en su Diccionario de uso del español, la corrupción posee múltiples significados: en estricto sentido denotativo se define como: "la acción y efecto de corromper", entendiendo este verbo como "quebrantar la moral de la administración pública o cambiar la naturaleza de una cosa volviéndola mala". También se identifica con la perversión, que significa " hacer moralmente malas a las personas". Sin embargo, la necesidad de conceptualizar este término de manera más precisa nos condujo a desprender un significado más amplio en su connotación, es decir, en cuanto a la precisión de su signo lingüístico, ya que finalmente este concepto es el que se amolda a la realidad social, puesto que la corrupción es para los grandes pensadores sociales un término eminentemente polisémico.

\section{Política y corrupción}

De acuerdo con Aristóteles:

... en el caso de las magistraturas, siempre que el régimen político esté constituido sobre la igualdad y la semejanza de los ciudadanos, vale la pena que las desempeñen por turno; primero porque, según es natural, piensan que prestan un servicio en su turno y que luego uno mira por su propio bien, como antes él mismo cuando gobernaba, velaba por el provecho de aquél. Más ahora, por las ventajas que derivan de los cargos públicos y del poder, los hombres tratan de gobernar continuamente, como si les aconteciera tener siempre salud a los que gobiernan estando enfermos; pues incluso en tal estado perseguirían con 
igual ansiedad los cargos. Es evidente, desde luego, que todos los regímenes que miran por el bien común son rectos, desde el punto de vista de lo absolutamente justo, y que cuantos atienden sólo a lo particular de los gobernantes son erróneos y todos ellos desviaciones de los regímenes rectos; pues son despóticos y la ciudad es comunidad de los hombres libres (Aristóteles, 1997: 119).

Así pues, en el mundo del pensamiento político griego, el meollo en el problema de la corrupción se identifica con lo que Aristóteles llama desviaciones y se centra básicamente en la confrontación de dos aspectos medulares: el poder contra la igualdad; y el bien común contra el interés individual. En este sentido entonces cambiar la naturaleza del Estado al buscar el provecho individual por encima del bienestar colectivo, perpetuarse en el poder para hacer uso de los privilegios que de él devienen en detrimento de los principios de igualdad y libertad conducen a regímenes políticos injustos y por tanto corruptos, ya que se pervierte el fin último del Estado que es el servicio a toda la sociedad. Entonces la lucha política entre los hombres dentro de un sistema corrupto se centra en la conquista del Estado para su utilización como instrumento de dominación de una minoría sobre toda la comunidad, y ello nos conduce inexorablemente al establecimiento de relaciones de poder entre congéneres, lo que fomenta en la praxis la desigualdad.

Por otro lado, Rosseau (1979: 31), que es otro de los grandes en el estudio de la política, al hablar de igualdad destaca este precepto como inherente al buen gobierno:

En el gobierno se encuentran las fuerzas intermediarias, cuyas relaciones componen la del todo con el todo, o del soberano con el Estado. Puede representarse esta última relación por la de los términos de una relación continua, cuyo medio proporcional es el gobierno. Éste recibe del cuerpo soberano las órdenes que transmite al pueblo, y para que el Estado guarde un buen equilibrio es necesario, compensado todo, que hay igualdad entre el poder del gobierno, considerado en sí mismo, y el poder de los ciudadanos soberanos por un lado y súbditos por el otro.

Si reflexionamos en esta verdad, podríamos inferir que si bien es cierto que el Estado posee la autoridad legítima para hacer cumplir la voluntad social, también lo es que si no se cumple con este precepto y se benefician sólo algunos cuantos del uso irrestricto de la autoridad, se pervierte el verdadero espíritu del Estado al conver-tirlo en un medio para que los gobernantes impongan sus intereses particulares.

Ahora bien para que ello no ocurra, debe existir un equilibrio entre el poder del Estado que obtiene de la sociedad y el poder de la sociedad 
que expresa de suyo la voluntad colectiva, en la medida que se logra alcanzar este principio homeostático se logra consolidar el pacto social que impide que la sociedad desaparezca por las contradicciones naturales que existen entre los grupos que la conforman. Bien dice Rousseau:

El súbdito permanece, pues siendo uno, pero la relación del soberano aumenta en razón del número de individuos, de donde se deduce que, mientras más el Estado crece en población, más la libertad disminuye (Rousseau, 1979:31).

Es decir existe una relación inversamente proporcional entre poder del Estado y soberanía.

De alguna manera, el problema de la corrupción surge entonces al plantearse el desequilibrio en la dicotomía Estado-sociedad, por ello a partir de este momento el gran dilema del pensamiento político es precisamente esta dialéctica. Engels planteó ya de una forma abierta la premisa de que la sociedad es por naturaleza antisocial o sea, que se encuentra inmersa en tantos conflictos que es incapaz de gobernarse a sí misma, y es precisamente por ello, que existe una razón por la cual los individuos llegan a un consenso general: debe existir un poder que se eleve por encima de la misma sociedad para mediar los conflictos entre clases sociales. En este momento surge el Estado, pero éste se convierte entonces en el objeto de la discordia.

Ahora bien este dilema finalmente nos conduce a la inevitable confrontación de los intereses individuales con los sociales y, por supuesto, a la contraposición del Estado y la sociedad. Al respecto Engels dice:

El Estado es más bien un producto de la sociedad cuando llega a un grado de desarrollo determinado; es la confesión de que esa sociedad se ha enredado en una irremediable contradicción consigo misma y está dividida por antagonismos irreconciliables, que es impotente para conjurarlos. Pero a fin de que estos antagonismos de clases con intereses económicos en pugna no se devoren a sí mismas y no consuman a la sociedad en una lucha estéril, se hace necesario un poder situado aparentemente por encima de la sociedad, que es llamado a amortiguar el choque, a mantenerlo en los limites del orden y ese poder, nacido de la sociedad, pero que se pone por encima de ella y se divorcia de ella más y más, es el Estado (citado en: Lenin, 1981: 3).

Si la principal causa de la lucha entre los hombres es el poder para obtener con él los privilegios que se derivan de su ejercicio, entonces en el nivel político la pugna intersocial se centra en la obtención del control del Estado para imponer la voluntad de un grupo sobre los 
intereses de toda la sociedad. Esta idea se puede encontrar claramente expresada en la obra de Guerrero:

Por tanto, la separación del Estado y la sociedad implica la distinción, por un lado entre vida pública y vida privada, y por el otro, entre intereses particulares e interés colectivo. Ya que el capitalismo creó al individuo desembarazándolo de las comunidades medievales, la sociedad civil es el seno en que se desenvuelve ese individuo y los intereses que, como intereses particulares, le son inherentes; el Estado por su parte, desprendido de la sociedad civil, asume las funciones generales, públicas, opuestas a las actividades particulares realizadas por los individuos de la sociedad civil (Guerrero, 1980: 79).

Este mapa evidencia el conflicto abierto que se desencadena entre los individuos que han logrado imponer su liderazgo y aquellos otros que rechazan el estado de las cosas y pretenden derrocarlos, para obtener los privilegios y beneficios que se derivan del uso y abuso de la autoridad.

La política así se convierte en el medio para acceder al Estado como instrumento de dominio y de subordinación; la vocación de servicio hacia la comunidad es relegada a segundo término y el Estado mismo se mira como un pasaporte para obtener el triunfo sobre los demás.

Desde el punto de vista político, el poder en sí mismo es necesario ya que sin él, el Estado no podría actuar, pero existen límites éticos que deben normar su ejercicio y la sociedad debe organizarse para definir esos límites a la autoridad del Estado, ya que por razones pragmáticas el gobierno siempre buscará tener más poder sobre los ciudadanos para perpetuar su hegemonía. Como se puede inferir de lo anterior, la acumulación del poder conduce a un potencial estado de violencia, por lo tanto debe mantenerse un sano equilibrio. Se reconoce pues la legitimidad del Estado para fijar límites a la libertad individual cuando ésta sobrepasa los derechos de otros, pero también queda establecido que las relaciones sociales entre los hombres se basan en el dominio y la servidumbre como preceptos fundamentales. Predomina el egoísmo y se utiliza a la política como medio para alcanzar el "éxito".

Ahora bien, en realidad el aspecto toral de este apartado, parece conducirnos no sólo a la separación de Estado y sociedad, sino también al reconocimiento de que esta escisión se establece sobre relaciones de poder entre los grupos sociales e individuos que integran de manera particular estos dos bloques. Parece necesario entonces determinar de qué manera los individuos consiguen el acceso al poder político en cada uno de estos campos, que en última instancia les permite 
establecer relaciones de autoridad y subordinación frente a sus demás competidores.

En el caso de México se debe asumir que en realidad el ejercicio del poder político se centra en el titular del Ejecutivo federal. Esta afirmación se basa fundamentalmente en el doble papel que juega el presidente de la república que se desempeña a la vez como titular de la administración pública - brazo ejecutor de la política de Estado- y como jefe del control político del país. Digo que se constituye en el máximo responsable de la administración pública en tanto que asume por mandato constitucional las atribuciones que le confiere nuestra Carta Magna para administrar el país, mientras que de facto asume un poder plenipotenciario que le permite nombrar a los servidores públicos de los tres poderes de la unión, rompiendo de esta manera el equilibrio entre los tres poderes de la nación y favoreciendo en todas sus decisiones los intereses del bloque en el poder.

Un modelo político de estas características, evidentemente tiene sustento en una serie de compromisos y complicidades que envuelven con un velo de misterio todas las manifestaciones de corrupción existentes en el quehacer gubernamental, puesto que de alguna manera los cargos públicos superiores se ejercen gracias a la voluntad única y suprema del primer mandatario, teniendo como condición en contrapartida, la sumisión y el servilismo. Este mismo esquema se reproduce en los niveles medios e inferiores, de manera tal que se entreteje una complicada madeja de contubernios e intereses en los que todo el Estado se transforma en defensor a ultranza del grupo político que detenta el poder.

Desde luego, se debe considerar que este modelo autocrático de hacer política cuenta con dos limitantes: su duración circunscrita a seis años y la imposibilidad de reelegirse para un nuevo periodo presidencial. Estos dos factores, lejos de atenuar las manifestaciones de corrupción, acentúan más este fenómeno, puesto que en ese lapso los grupos políticos que arriban al poder, procuran acelerar en su favor la acumulación de riquezas, mediante el uso irrestricto de la autoridad del Estado y el aprovechamiento personal de los recursos colectivos.

La inseguridad y el malestar que le provoca al grupo en el poder la certeza de que en un lapso determinado todo habrá de acabarse, lo conducirá al hundimiento de la moral pública. Por eso, los burócratas se mueven dentro del mundo político con la seguridad de que ellos 
pueden utilizar la corrupción para reivindicar su inseguridad económica, tal y como lo hicieron sus antecesores y tal y como lo harán los que los sucedan. Ellos tienen la seguridad de que nada puede cambiar al sistema y por tanto existe una aparente fatalidad que los hará cómplices de los que usufructúan el poder en favor del grupo del cual forman parte, para encubrirse y garantizar su impunidad.

Se establece así una actitud de contubernio, de convencionalismo y de aceptación obligada a no ser diferente con los otros miembros del grupo, y aquel que osa desafiar el sistema, se convierte en sujeto de desconfianza, en traidor, y el grupo político se muestra hostil y brutal al aplicar castigos a las personas que no son como ellos.

Esta deformación da como resultado que la política se convierta en sinónimo de violencia, en un medio de ganar dinero, ya que para una sociedad como la nuestra lo práctico es lo que da dinero, y si la política da dinero entonces a todo el mundo le interesa. Se bifurca entonces la brecha entre poder político y ética, entre lo real y lo ideal. La pragmática rebasa la concepción ideal de una política al servicio del pueblo, por contraponerse a los fines egoístas difundidos en todos los niveles de la sociedad, no importan las repercusiones morales de nuestros actos políticos lo importante es conseguir el éxito sin importar los medios.

De ahí que en general todos los grupos políticos luchan para ser poderosos e importantes, para controlar los destinos de todos hacia la concepción particular que tienen de ver las cosas, no importan los deseos de los demás, lo primordial es obtener el dominio del aparato del Estado y obligarlos a caminar hacia su rumbo. Y con esta visión los grupos diseñan todo tipo de trampas ideológicas para convencer a la mayoría de que ellos son los dueños de la verdad absoluta, de que ellos sí representarán los intereses colectivos.

\section{Partidos políticos}

Desde mi particular punto de vista, el punto central de este apartado, radica en la declaración de los partidos políticos en cuanto a sus principios doctrinarios, cuestión que sirve como marco de referencia para permitir a la sociedad valorar el grado de representatividad que tiene en cuanto a sus intereses y creencias; y también la congruencia que guarda su ideología con las acciones y estrategias aplicadas por ese partido a la realidad política del país. 
La corrupción en este terreno se traduce en la transformación de las motivaciones ideológicas que inducen a los grupos sociales a participar en la lucha política, en intereses particulares de los individuos que detentan el poder dentro del partido, dando inicio así a la superposición del beneficio egoísta por encima del bien común de los sectores que conforman al partido político.

Es imposible dejar de reconocer que en el caso de México, los partidos tienden a utilizar a los grupos sociales como escalón para lograr el triunfo electoral, pero no se preocupan por incorporar las demandas colectivas a su plataforma ideológica, en tal caso los grupos que detentan el poder dentro de ellos se enquistan impidiendo al resto del grupo permear los niveles jerárquicos más altos y distribuyen los cargos obtenidos sólo entre aquellos que comparten sus intereses directamente. Los líderes permanecen en sus candidaturas por años, convirtiéndose en los candidatos "morales" de los partidos

Frente a esta perspectiva no se puede hablar de democracia dentro de los partidos, puesto que los mismos carecen de bases dentro de la sociedad, y los grupos políticos minoritarios que representan tampoco eligen a sus representantes por votación directa, sino que les son impuestos.

Se pudiera citar en este caso a Delhumeau (1970: 35) que al respecto nos dice:

De la eficiencia con la cual logra cada partido la conversión de su interés particular en interés general depende en alto grado su poder y legitimidad y, en síntesis, su eficacia política como plataforma para la elección de los representantes de la unidad nacional. Con frecuencia los dirigentes de un Partido político pertenecen a un mismo y determinado sector social, y al mismo tiempo incorporan de manera efectiva expectativas propias de otros sectores. En la medida que este desenvolvimiento es más real e intenso se incrementan los procesos de democratización y representatividad, y con ellos las posibilidades de supervivencia y fortalecimiento del Partido. La democratización práctica consiste, en este sentido, en la incorporación de intereses y expectativas (económicas y sociales) propios de los diversos sectores, por un sector político dirigente y conciliador.

En el fondo de este problema, subyace un conflicto que nos remite a la dialéctica primaria entre bien común e interés individual, puesto que entonces los partidos políticos buscan la obtención del poder no como la forma de hacer prevalecer la igualdad o por lo menos disminuir las diferencias económicas y sociales entre los individuos, sino por el contrario para ejercer esa autoridad que deviene del uso exclusivo del 
aparato del Estado para hacer prevalecer el interés de un grupo sobre los otros. Desde luego que esta posición se niega, se disfrazan las verdaderas intenciones del grupúsculo que utiliza a los que votan por él para luego imponerles su voluntad, pero esta posición a final de cuentas lo único que consigue es polarizar un conflicto que después es evidente.

El equilibrio social siempre irá en relación directa con el grado en que se satisfacen las demandas de los grupos mayoritarios, pues en esa medida se atenuarán los conflictos entre clases sociales. Al respecto pudiera citarse a Coser (1961: 45):

La negación del conflicto social dentro de un partido político, y de éste con relación al exterior, polariza a aquellos que viven la tensión como un hecho realy que intentan entonces reivindicar su desacuerdo (manifiesto o latente) y mostrar sus evidencias, radicalizando el conflicto. En una palabra, a mayor negación, devaluación y rechazo de las discordias sociales, mayor intensidad del desequilibrio conflictivo.

Una perspectiva de cerrazón para hacer frente a la inconformidad de los demás grupos que luchan por obtener el poder como la única alternativa de solución a sus problemas de subsistencia diaria lo único que acarrearía sería la violencia social, en lugar de una lucha política pacífica.

La burla agrede en cada hombre su sentido personal de impotencia para alterar las condiciones bajo las que sufre; disminuye su poco desarrollado respeto de sí mismo; le recuerda su status acostumbrado, con los consiguientes sentimientos de deferencia hacia quienes tienen autoridad sobre él. Le recuerda que él es el súbdito y otros los gobernantes, y le sugiere que esta dicotomía es eterna como la naturaleza misma (Sampson, 1975: 14).

Bajo esta perspectiva, el ciudadano común se puede transformar, su conducta se convierte en una actitud peligrosa y se puede esperar cualquier cosa.

Es muy discutible la existencia de diferencias de todo tipo entre los hombres, la experiencia ha demostrado que hasta el momento no existe un régimen político totalmente igualitario, sin embargo, lo que es indiscutible es que sí es posible disminuir las diferencias entre clases sociales, independientemente del modo de producción que prevalezca en esa sociedad, siempre y cuando verdaderamente la acción del Estado sea equitativa al momento de satisfacer todas las demandas de los grupos que la conforman y proteja verdaderamente las normas mínimas de bienestar colectivo. Este tipo de sociedad existe, no es 
imaginario, tal es el caso de Suecia, Suiza y otros países desarrollados en los que se manifiesta un proceso deliberado de cambio social que persigue como objetivo último la igualdad de oportunidades económicas, sociales y políticas entre los individuos, mismas que se traducen en altos niveles de bienestar social.

La dimensión de la igualdad adquiere objetividad en lo individual, porque entonces:

La ley moral se apoya en la posibilidad de que cada ser humano se desarrolle, en mayor o menor grado, en una dirección u otra". El individuo podrá buscar cómo ordenar su vida y sus relaciones con los demás, a partir del amor o el poder. En la medida en que desarrollemos nuestra capacidad de poder, debilitaremos nuestra capacidad de amar y, a la inversa, en la medida en que aumente nuestra capacidad de amar, aumentará nuestra incapacidad para el éxito en la competencia por el poder. En la medida en que las fuerzas del amor triunfen sobre las fuerzas del poder, prevalecerá la igualdad entre los hombres: y, a la inversa, en la medida en que las fuerzas del poder dominen a las fuerzas del amor, las relaciones humanas se caracterizarán por la dominación y la servidumbre (Sampson, 1975: 8).

Aquí desde luego el concepto de amor se remite al sentimiento de comprensión hacia los demás, al hecho de reconocer que también los otros miembros de una sociedad tienen derecho a poseer satisfactores básicos a sus necesidades y también a expresar su voluntad en la búsqueda del bien común.

Tal y como lo afirma Heráclito, en su teoría sobre la final armonía de los contrarios o la unión de los opuestos (Xirau, 1995: 27), en esta vida todo funciona bajo una dualidad pero es este hecho lo que le permite fluir a la energía y materia, al cosmos, tesis y antítesis son dos facetas de un mismo fenómeno. Desde esta perspectiva entonces poder y amor debieran ser una forma de expresión de la política, fusión de valores individuales con los colectivos, intensidad en el intercambio de comunicación de necesidades a satisfacer, armonía en la creencia de métodos compartidos para la consecución del bien común.

La política idealmente debiera buscar el justo punto de equilibrio entre las dos fuerzas, debiera ser un arte para conjugar de la manera más equitativa posible, las necesidades del individuo con las de la comunidad en la que vive. Del éxito o fracaso en esta labor dependerá la aparición de la corrupción como un fenómeno que expresa el desajuste entre el ser y el deber ser. 
Bajo tales circunstancias sólo puedo afirmar que el impulso egoísta de acumulación lo podemos controlar y equilibrar mediante nuestra conciencia e identidad social, el impulso de gratificación a nuestras necesidades básicas debe ir más allá de nuestro organismo, el amor hacia nuestros semejantes aumenta e intensifica la gratificación instintiva del ser humano, permitiéndonos trascender a un estado placentero que nos permitirá sentirnos alegres, satisfechos y con ganas de compartir vivencias con los demás.

Es lógico que si los grupos políticos formales difunden valores materiales como la norma básica de convivencia de una sociedad, los principios, las normas y las creencias éticas queden relegadas a unos cuantos que no son enajenados por este proceso.

Desde este punto de vista entonces la corrupción es ante todo una manifestación de la patología existente, es un fenómeno que promueve la adicción al egoísmo político, es un suceso que promueve la generación de una anticultura bajo condiciones extrañas que relacionan a los individuos, para lograr fines perversos y ajenos a los fines socialmente aprobados.

Por ello, la política debe ser un arma de la sociedad empleada contra el poder omnipotente del Estado totalitario la liberación en contra del egoísmo generalizado sólo puede lograrse mediante la organización civil en contra de las prédicas ajenas a nuestro verdadero espíritu colectivo. La permanencia irresponsable y el argumento, tan falaz como viejo, de los poderosos que justifican su función apelando directamente a su poder y enarbolando la debilidad e ignorancia de sus oponentes como justificación para perpetuarse en él, no debe legitimar su proceder frente a una sociedad que cada vez debe estar más politizada y participativa.

El poder no debe aplicarse ciegamente, sino por el contrario compartirse con la sociedad para lograr un sano equilibrio. Si el Estado no comprende lo anterior, entonces la única salida que tiene la sociedad para lograr este equilibrio será organizarse y hacer valer su derecho a la soberanía popular, ello constituirá la mejor garantía para tratar de igualar políticamente las oportunidades para todos los mexicanos. En este proceso sería conveniente que la sociedad buscará organizarse políticamente, de acuerdo con la "democracia" capitalista que existe en nuestro país, mediante la creación de un partido exclusivamente civil, integrado con personas que no hayan pertenecido a ningún 
partido político de los ya existentes, para evitar que se contaminen con la inmoralidad que caracteriza a todos nuestros políticos, de la misma forma que lo hacen ellos cuando algún ciudadano común y corriente trata de ingresar en las filas de esas instituciones.

\section{Democracia}

Para Aristóteles, la democracia consistía en que el pueblo fuera el que gobernara, que todos mandaran a cada uno de acuerdo a la voluntad popular y cada uno a todos alternativamente. En la democracia-decía él mismo-el derecho político es la igualdad. En nuestra Constitución se encuentra plasmada esta concepción aristotélica de régimen político en la que el pueblo es gobernante y gobernado, se consagra la división de poderes, el principio de sufragio universal para elegir a nuestros gobernantes y representantes, y el pluralismo ideológico para garantizar la alternancia en el poder de diferentes corrientes políticas en nuestro país.

La cuestión aquí es que existe un desfasamiento entre el ser y el deber ser. En México, la Constitución se convirtió en letra muerta desde el momento mismo en que fue creada, los gobiernos posrevolucionarios nunca aplicaron el modelo de país que quedó plasmado en la Carta Magna, aunque en el terreno ideológico y en la retórica oficial se diera por hecho que sí existía. Consecuentemente el surrealismo político se convirtió en la bandera dogmática de estos gobiernos.

Algunos políticos argumentan que los preceptos constitucionales ya no tienen validez por ser obsoletos, pero en este caso yo alego que nunca fueron llevados a la praxis, y por tanto no se les dio la oportunidad de demostrar su operancia, puesto que vivimos sumergidos desde 1917 en la antítesis del proyecto de país que formalmente existe en la carta magna. La república mexicana sólo existió en el papel, pues la república es hija de la democracia y el federalismo, conceptos abstractos que no han podido manifestarse en el mundo real.

Así pues, la verdad y el reconocimiento exacto de una realidad social debe conducir al concepto de equilibrio entre sociedad y Estado, no se puede gobernar para unos cuantos bajo la égida de un poder absoluto, el pacto social es fruto de la voluntad popular para reconocer una autoridad que imponga el orden y el equilibrio en la búsqueda del 
bien común, y que conste que éste es un principio válido para cualquier tipo de sociedad humana. La experiencia de países con un modo de producción socialista como el de la exURSS o de otros con un modo de producción capitalista bajo un régimen militar-como hubo muchos en Latinoamérica, África y Asia- demostró que los gobiernos organizados en forma de dictadura están condenados al fracaso por su distanciamiento con la sociedad a la que supuestamente sirven y no por la forma de organizar sus estructuras económicas, ésa es la verdadera lección. Finalmente las contradicciones que engendra un régimen político de este tipo conduce inevitablemente a la extinción de los gobiernos instituidos contra una mayoría oprimida y explotada, puesto que obliga a la sociedad misma a luchar, ya sea por medios pacíficos o violentos, contra una desigualdad extrema, una muestra de ello la encontramos en Indonesia con la caída del dictador Suharto. El concepto de lograr un sano equilibrio entre el Estado y la sociedad cobra importancia extrema.

La democracia sin igualación significa hipocresía sin limitación, significa degradación de la ciencia de Estado a simple politiquería individualista, significa el mantenimiento costoso de una burocracia que no sólo incumple sus propósitos, sino que además explota el ejercicio de la autoridad en su propio beneficio haciendo de la vida pública una charca de corrupción.

Por ello y en ejercicio de la soberanía consagrada en nuestra Carta Constitucional como voluntad de los mexicanos, se hace necesario lograr la participación directa de la ciudadanía en los actos de gobierno y esta lucha debe quedarnos bien clara, ya que en la medida que nos organicemos civilmente contra los actos de gobierno, injustos para la mayoría, lograremos frenar la utilización del poder del Estado en beneficio de un pequeño grupo privilegiado. Desde luego, no se trata de caer en situaciones extremas sino más bien de que la sociedad que ha conferido un voto de confianza a sus autoridades, representadas en los poderes de la Unión, en contraparte tenga el derecho de exigir a las mismas el buen desempeño de su función y por supuesto, su estricto apego al orden legal vigente.

El Estado se debe a la sociedad que le ha conferido el poder, pugnando siempre por lograr el bienestar colectivo, tergiversar este mandato representa el más despreciable acto de corrupción política. Por ello, se debe considerar la creación de una organización ciudadana 
para la defensa de la sociedad en su conjunto, que se encargue de evaluar y fiscalizar los actos del Estado, de establecer programas integrales de combate a la corrupción y a la violencia, de organizar a la ciudadanía para evaluar los programas gubernamentales en relación con el bienestar colectivo y sobretodo, de detectar las necesidades reales de todos y cada uno de los grupos sociales para incorporarlas a la gestión gubernamental, estableciéndole un orden necesario de prelación, de acuerdo con el sentir de la mayoría, y para ello dispone del referéndum y el plebiscito, que por cierto son herramientas que jamás han sido usadas por los gobiernos posrevolucionarios en México, ya que la democratización no es afín a los regímenes autoritarios.

No se trata de imponer por medios violentos, o de reproducir un esquema de autoridad y subordinación sobre el Estado, sino de equilibrar las fuerzas, de que la comunicación fluya libremente en ambos sentidos, de compartir la responsabilidad por alcanzar los objetivos comunes.

Así pues, el organismo propuesto deberá crearse y sostenerse con recursos de origen público para garantizar su imparcialidad y además se debe evitar la hegemonía de alguna fracción social en su dirección, por lo cual se debe integrar con representantes elegidos democráticamente en las diferentes asociaciones civiles que integran la sociedad, bajo la asesoría de representantes de las principales instituciones académicas de investigación de la problemática social.

Esta organización ciudadana estaría dirigida por un consejo nacional integrado por tantos miembros como estratos sociales representativos de los intereses específicos de grupos existan en el país, que se eligirían directamente dentro de las instituciones ciudadanas que representan a cada sector. La duración de su periodo de representación pudiera equipararse al tiempo político de la nación, que es de seis años. Sin embargo, la presidencia y por tanto la dirección de este consejo, deberá alternarse anualmente entre sus miembros a fin de garantizar la equidad y democracia en la aplicación de sus programas de trabajo. Se trata pues de un verdadero ejercicio de la soberanía popular frente al poder del Estado, se busca equilibrar la relación de fuerza política entre Estado y sociedad, obligando al primero a respetar la voluntad de una mayoría y no de una minoría privilegiada. 
Finalmente podemos afirmar que la política no sólo debe ser democratizadora sino también racional e inteligente. Racional en la medida en que la sociedad induzca al gobierno a adecuar los medios públicos al cumplimiento del fin ético del Estado que es la obtención del bien común; e inteligente en la medida que la sociedad convenza al Estado para cederle pacíficamente las funciones de evaluación de la gestión pública y de detección de las necesidades que deben satisfacerse prioritariamente, antes de que surgan condiciones adversas de gobernabilidad.

Pero ello implica despojar a los gobernantes del egoísmo instintivo que los caracteriza y que los conduce a propiciar una flagrante desigualdad social, a final de cuentas debemos entender que el hombre es un animal cívico, tal y como lo dijo Aristóteles (1997: 185):

Por consiguiente, todos los sistemas encierran un cierto grado de justicia, pero en términos absolutos, están equivocados; y por esa razón, cuando los ciudadanos no intervienen en el régimen, de acuerdo a la idea que cada cual pueda tener, se rebelan. Y con más derecho que todos podrían rebelarse, aunque menos suelen hacerlo, los que son diferentes en virtud; pues es muy razonable que sólo ellos son absolutamente desiguales. En cambio, hay algunos que por sobresalir en imagen, no se juzgan merecedores de un trato de igualdad debido a esa desigualdad; y es que se piensa que son nobles los que tienen en su haber la virtud y riqueza de sus antepasados.

Recuperar la moralidad pérdida, regresar a los valores que nos dieron patria, incorporar a la sociedad mexicana al ejercicio del poder público es una lucha que debemos enfrentar todos los mexicanos si queremos acabar con la corrupción.

Quiero terminar este apartado con los sabios conceptos vertidos por Morelos en el Decreto Constitucional de Apatzingán, a manera de reflexión de todo lo expuesto:

La facultad de dictar leyes y establecer la forma de gobierno que más convenga a los intereses de la sociedad, constituye la soberanía. Como el gobierno no se instituye por honra o intereses particulares de ninguna familia, de ningún hombre o clase de hombre, sino para la protección y seguridad general de todos los ciudadanos unidos voluntariamente en sociedad, ésta tiene derecho incontestable a establecer el gobierno que más le convenga, alterarlo, modificarlo o abolirlo totalmente cuando su felicidad lo requiera. Por consiguiente, la soberanía reside originalmente en el pueblo (Rodríguez, 1992: 170). 


\section{Sociedad y corrupción}

La desorganización social no se da sólo en el contexto político, desde el punto de vista estrictamente sociológico este concepto abarca variados fenómenos como el conflicto entre lo individual y lo social, el desajuste entre los fines socialmente aprobados y los medios para lograrlos. De ahí que sea necesario examinar la corrupción del aparato público considerando estas variables, no sólo porque la sociedad se ve afectada directamente por sus efectos sino también en ocasiones por propiciarla y tolerarla.

Así pues, la complejidad del fenómeno en cuestión se traduce en una forma de desorganización social, que implica la existencia de relaciones contradictorias en otros niveles:

La desorganización social es un concepto que abarca variados fenómenos como el conflicto social, el conflicto de culturas, el desajuste entre medios y fines socialmente aprobados, y otro tipo de incompatibilidades o contradicciones. Los grupos o individuos que están más expuestos a las presiones generales por estas formas de desorganización son más susceptibles de violar las normas sociales. Sus reacciones dependen de los valores, expectativas y necesidades que llevan consigo cuando se enfrentan a las particulares dificultades que les crean sus circunstancias (Chinoy, 1968: 75).

En efecto, la corrupción como una forma de la expresada desorganización social se refleja específicamente en el choque que se da entre los intereses del hombre como individuo y los que posee como integrante de una sociedad, lo cual evidentemente implica la satisfacción de sus necesidades particulares en contraposición con los valores sociales y las necesidades colectivas existentes. Esto representa la dicotomía hombre-sociedad, que sin embargo no conduce a una ruptura o negación de esta dualidad, sino a la racionalización de este conflicto, aunque lleve implícita la adopción de una forma de conducta desviada que puede ser la corrupción. En estas situaciones, "las racionalizaciones se incorporan a la cultura como normas de conveniencia, ayudando a perpetuar la existencia de valores incompatibles a pesar de la inevitable necesidad de ignorar cualquiera de ellos" (Chinoy, 1968: 373).

Es precisamente en esta problemática donde se pierde la conciencia del servicio público en aras del beneficio personal, sirviéndose del poder para ascender en la escala social y convirtiendo a este hecho, en un acto tolerado por los particulares, siempre y cuando se beneficien también con ello. 
Desde este punto de vista, la inmoralidad se manifiesta no sólo en el servidor público que incumple su función en la búsqueda de un beneficio particular, sino también en el ciudadano que evade su responsabilidad al incurrir en una conducta desviada de las normas socialmente aceptadas. En el primer caso, el individuo busca por lo general un beneficio económico aceptando los riesgos que conlleva una acción ilícita, y en el segundo se busca no afrontar la sanción que se debe aplicar y a cambio corresponder con una dádiva que la elimine. Como se ve, en ambos casos se propicia la supremacía del fin individual sin importar los medios ni los intereses colectivos, se pretende establecer el egoísmo sobre el bien común y en consecuencia de la ilegalidad sobre el imperio de la ley.

En este hecho el meollo del asunto es resaltar que la sociedad misma al tolerar la existencia de medios amorales para evadir su responsabilidad por la comisión de ilícitos, se hace cómplice de esa conducta desviada y por tanto, de la aceptación implícita de la corrupción como forma de vida.

De esta manera, resulta de sumo interés comprobar que no es atribuible únicamente al gobierno la corrupción, puesto que en ese interactuar que existe entre el Estado y la sociedad fluyen las conductas inmorales en ambos sentidos y si es cierto que en el caso de México malos funcionarios públicos se han enriquecido con actos inmorales, también lo es que prominentes empresarios y ciudadanos comunes en complicidad con ellos han obtenido grandes beneficios económicos.

Por otra parte mientras no se tenga bien claro el precepto de igualdad en la aplicación de las disposiciones socialmente aceptadas no se puede hablar de una sociedad organizada. Esta cultura de la desorganización social en la que se concentran ideas históricamente determinadas, respecto a los objetivos e intereses que el individuo debe buscar, no limita los métodos que se deben utilizar para alcanzar los fines socialmente aceptados, definidos por supuesto en términos de riquezas materiales, sino por el contrario otorga una amplia discrecionalidad tanto al ciudadano común, como al servidor público, soslayando los valores morales y fomentando la competencia entre los individuos para alcanzar el éxito y por ende el prestigio social que se constituye en el fin último de la persona. Por eso el Estado es el principal promotor y difusor del amor a lo material y lo individual, en la medida que logra inducir estos patrones de conducta en los ciudadanos 
encontrará menor oposición para ejercer autocráticamente las acciones de gobierno y reproducirá ampliamente el sistema de acumulación desigual de las riquezas.

Por todo lo anterior, resulta por demás acertada la afirmación de Sorokyn cuando dice que:

La organización social sólo puede subsistir cuando el individuo puede internalizar los valores y significados sociales y los adopta como suyos propios, proyectándolos en el marco de la ley que se obliga a respetar, por convencimiento o por imposición del gobierno (Sorokyn, 1967: 19).

En efecto, solamente induciendo al individuo el concepto de valores éticos y morales socialmente aceptables es posible disminuir los efectos perniciosos de la conducta desviada.

Al considerar las creencias colectivas y los valores generales de una sociedad como un elemento de indiscutible importancia de la existencia colectiva, no debemos olvidarnos que esa sociedad se integra por individuos que se interrelacionan, en particular y a través de grupos, y que por tanto esa cultura abstracta se concreta en las acciones de las personas como seres individuales. Esto nos indica que el hombre en sí es más que un conglomerado de creencias, valores o costumbres que responden a factores culturales únicamente, puesto que de hecho existen una serie de potencialidades biológicas que determinan también nuestra capacidad de aprendizaje dentro de la sociedad. Este conjunto de elementos se organiza dentro de una estructura interna en cada individuo conocida generalmente como personalidad.

Aunque este reconocimiento de las bases fisiológicas y anatómicas de la personalidad evidencia la tenue separación que existe entre las necesidades formativas individuales y las grupales, no se puede negar la importancia que tiene aceptar que sus principales componentes -costumbres, valores, creencias actitudes, etcétera- derivan principalmente de la cultura, mediante las relaciones sociales.

\section{Psicología y corrupción}

Retomando la hipótesis de que el individuo es producto de sus potencialidades físicas, pero que esta dotación biológica sólo adquiere sentido dentro de un ambiente en constante cambio, constituido tanto por su entorno natural como por su cultura y la sociedad misma, entenderemos la relación dialéctica que se establece entre estas 
instancias, por ello es aquí en donde el concepto de desorganización social adquiere su verdadera dimensión.

Sin embargo, es evidente que los atributos particulares de cada persona varían su respuesta frente a las exigencias y normas culturales de los demás, dependiendo de los aspectos individuales internos que conforman la personalidad del individuo, y que básicamente son dos: el carácter y el temperamento. El primero se refiere a aquellos aspectos que regulan el comportamiento del individuo y que son inducidos externamente desde su entorno social -familia, escuela, religión, cultura-. El segundo agrupa las estructuras del sistema nervioso que están sujetas a las leyes genéticas del ser humano.

En este caso, me remitiré al análisis de las variables sociales que influyen en la conducta de las personas, ya que los cambios estructurales debidos a factores fisiológicos de los individuos, obviamente se deben a las alteraciones del medio interno del organismo y por tanto no es de interés para efectos del presente estudio. Si bien es cierto, que una conducta desviada de etiología biológica puede provocar alteraciones del orden social, el análisis y tratamiento de ese individuo se remite al campo de la psiquiatría básicamente.

No obstante lo anterior y tomando en cuenta la importancia de analizar la personalidad del individuo como el factor determinante de su comportamiento y actitud frente a los patrones de conducta colectivos que conducen a la desorganización social, consideraremos los aspectos psicológicos individuales y su vinculación con la sociedad misma, para explicarnos las interrelaciones que condicionan la aparición del fenómeno de la corrupción como una forma de conducta desviada.

\section{El esquema intrapsíquico.}

A efecto de conceptualizar el concepto de psicología individual, desde este punto de vista pudiéramos aludir el modelo de Freud (Jones, 1969:192 y 193) que concibe a la personalidad como resultado del equilibrio de fuerzas contradictorias respecto a la conciencia, racionalidad y moralidad. De esta manera es concebida la personalidad como la resultante de tensiones dinámicas. En realidad, la personalidad del individuo constituye su propio "yo", pero tiene ciertas implicaciones: por una parte está la presión del impulso y el deseo inmoral que se encuentran en el inconsciente, constituyendo el 
"ello"; por la otra, se encuentran en oposición todas las normas, costumbres y creencias que son inducidas desde el exterior por la sociedad para integrar al "super yo" en el terreno de la conciencia.

En este sentido, la función del "yo" es mediar entre estas dos fuerzas catéxicas y por tanto, como ya se dijo, la personalidad del individuo es el resultado de este equilibrio razonado entre el instinto y la conciencia.

El mecanismo que se desencadena entre estas tres instancias, se centra en la consideración de que el "ello" no sólo proporciona energía a la líbido sino que también impulsa al "yo" a buscar la satisfacción individual, el placer y el poder sobre otros; y de la misma manera desencadena simultáneamente en el "super yo"un sentimiento de culpa que provoca la represión y el control consciente de los deseos instintivos, de acuerdo con los valores sociales que moldearon su personalidad.

La razón ubicada en el "yo" consciente e inteligente es la mediación entre estas dos fuerzas contrapuestas, que pueden desencadenar formas de conducta patológica individual y socialmente, cuando se llega a dar un proceso de aplanamiento de una sobre la otra. Las exigencias morales en exceso y dar rienda suelta a nuestros deseos primarios indefectiblemente nos conducirán a un estado entrópico y por tanto a un desequilibrio mental.

Sin embargo, no debemos olvidar que el "yo" debe su origen a la percepción del mundo exterior real y en consecuencia de esa relación que se establece entre mente y realidad objetiva pueden surgir estados patológicos del ego, si esa relación se funda en la anulación o relajamiento del entorno social.

En realidad, de acuerdo con la teoría freudiana el problema clave se centra en la existencia de dos o más necesidades contrapuestas que se muestran como realidades incompatibles. Conforme se incrementa la fuerza de esa dicotomía, se aleja la realidad y se pierde la alternativa de una acción consciente y razonada, se refuerza la noción de satisfacer nuestros deseos más primarios y la realidad social se hace progresivamente más confusa hasta llegar a manifestarse como una conducta desviada en el individuo.

Finalmente, desde el punto de vista del esquema intrapsíquico de Freud se establece que estas contradicciones son la causa de la 
patología individual, pero en realidad en el fondo subyace una contraposición en lo que aparece como su interés colectivo y su interés particular. Fenómeno que se traduce en la oposición entre una necesidad de cooperación cada vez más necesaria y el egoísmo, también cada vez más intenso, promovido desde las estructuras de la sociedad misma.

En esencia dentro de la praxis, se fomenta en nuestro país el individualismo y la competencia absurda entre los hombres, se establece lo material como eje de la civilización. El dinero es la abstracción de la riqueza producida por todos, por eso se le convierte en el fetiche que debe regir nuestras acciones.

Como efecto de esta norma socialmente aceptada, se provoca el malestar individual y cada gesto de violencia genera otros recíprocos hasta llegar a extremos insospechados. En este proceso no se hace distingo de ninguna clase, los marginados buscan la riqueza material a cualquier precio y los poderosos se atemorizan ante sus competidores y tratan de acumular más y más riquezas materiales, dando así inicio a un proceso de polarización social.

Desde esta perspectiva en el ámbito del sector público, existen dos elementos que deben considerarse en la psicología del burócrata: la falta de seguridad en el empleo, como ya se mencionó anteriormente, y los bajos salarios con los que retribuyen su trabajo. Por una parte, la necesidad instintiva de allegarse los medios de vida que satisfagan sus necesidades básicas y por otra la incertidumbre de permanecer en un puesto determinado que le procure recursos para la subsistencia diaria. Este tipo de trabajo constituye una permanente insatisfacción e inseguridad en sí mismo, a esta frustración por el trabajo se añade el fracaso en la consecución de los anhelos que le son inducidos a través de la sociedad y que se traducen en una permanente contradicción, en tensión emocional, en irritación contra el mundo y contra sí mismo, en deseos destructivos.

De esta manera, se entra a la forma de vida neurótica, en una etapa de violencia e inconformidad por lo que somos y en una búsqueda difícil, permanente y desgastante por conseguir la riqueza material que nos permita identificarnos con el prestigio social que rige como los valores hegemónicos en la sociedad misma.

Así las cosas, el servidor público sufre una transformación psicológica notoria, por un lado aisla sus intereses de los intereses 
colectivos y por otro su potencial agresividad neurótica se cristaliza con su ímpetu de atesorar el mayor poder y los ingresos posibles para el día de hoy, puesto que mañana si pierde el empleo no tendría esa posibilidad.

Es por ello que estos individuos se convierten fácilmente en autócratas que canalizan su frustración y agresividad hacia los demás mediante un trato despótico hacia los miembros de la comunidad que supuestamente debería de servir. La vocación de servicio así es transformada en un síndrome de ansiedad por la necesidad irracional e inconsciente de acumular bienes y autoridad sobre los demás. La personalidad del burócrata se caracteriza entonces por una sociopatía extrema: para él no existen las normas sociales, culturales, religiosas o familiares; carece de conciencia moral; es servil con sus superiores y despiadado con los subordinados y el público; es conformista y poco creativo en su trabajo; su única ambición es ocupar un puesto que le permita enriquecerse; aplica día con día la ley del menor esfuerzo, apegándose estrictamente a sus rituales diarios y la inestabilidad laboral le convertirá en una persona obsesiva en el mantenimiento de su cargo a costa de lo que sea, incluyendo traiciones, prostitución laboral y servilismo extremo.

Desde luego, estamos hablando de un prototipo extremo de burócrata y en el terreno de la realidad, no necesariamente encontraremos juntas estas características en cada caso, su combinación variará de acuerdo con las condiciones específicas que hayan influido en la conformación de la personalidad del individuo de que se trate.

Así pues la aceptación del individualismo como norma rectora de nuestro consciente, la corrupción prevaleciente como un valor entendido en la realidad, la transgresión de valores que rigen el "super yo", la obtención de dinero y poder como objetivos del éxito social que refuerza nuestra autoestima; y saltar escalones trepando en las espaldas del prójimo se convierten en premisas que rigen la vida de los individuos perversos, la naturaleza humana es transformada y se convierten en sujetos moralmente malos, en la medida que sólo ven por sí mismos sin importarles los demás.

Este patrón de comportamiento, provoca una constante insatisfacción con uno mismo, una negación de lo que somos y una búsqueda irrefrenable por lo que no somos. Se da una lucha individual 
encarnizada y hasta la corrupción es válida dentro de este combate. En la mayoría de los casos, a la frustración de no conseguir lo que deseamos nos provoca un sentimiento de envidia y reprobación hacia los individuos que adoptan conductas desviadas, pero cuando nosotros accedemos a ocupar una posición que nos coloca en la posibilidad de apropiarnos de la riqueza colectiva, lo hacemos sin ningún miramiento, sabedores de que quienes nos precedieron en este esfuerzo violaron las conveniencias sociales y permanecen impunes a la acción de la justicia más elemental.

La realidad colectiva entonces es transformada en un mundo de fantasía y apariencia por los hombres que satisfacen sus deseos primarios en su calidad de individuos aislados, perdiendo su identidad y necesidad de pertenencia a una sociedad. Sienten la vida comunal como un obstáculo para desarrollar su capacidad como individuos y por lo tanto, como un estorbo para alcanzar ese mundo de riquezas que les daría un estado de paz y felicidad. El deseo de convivencia y copeeración con su comunidad es convertido en un odio hacia el trabajo en grupo.

\section{Poder}

Retomando el punto anterior, la frustración tiende a convertirse en violencia hacia los demás y por tanto en terreno fértil para la desorganización social. En sí misma la violencia es poder, tal y como lo afirma Mills: "La violencia es manifestación de poder, es posesión de instrumentos de fuerza y política, es una lucha por el poder: el tipo definitivo del poder es la violencia" (Mills, 1969: 166).

Entonces se concibe a la violencia como el único medio para establecer mecanismos de poder entre los individuos y no podía ser de otra manera, puesto que alguien que quiera dominar a otro congénere, sus actos o sus propiedades sin contar con su voluntad, está cometiendo un acto violento. Como ya se afirmó anteriormente, cuando una persona descubre que el uso de la violencia le reporta beneficios exclusivos o le permite desahogar su cólera sin consecuencias graves, es probable que recurra a ella con mayor frecuencia.

En efecto si no existe alguna forma establecida por el Estado que representa el orden institucional para que los miembros de la sociedad observen una conducta apegada a los ordenamientos jurídicos, y lejos de ello el Estado mismo se convierte en el primer transgresor de las 
leyes, es evidente que el ciudadano común no encontrará una razón para la observación de la normatividad vigente y por tanto tenderá a adoptar patrones de violencia individualmente.

Las causas exógenas generadoras de violencia, de esta manera crean las condiciones dentro de las relaciones sociales para que el individuo actúe violentamente. Esta violencia está en relación directa con los logros personales: "El éxito, el afán de dominio, la fama, la gloria, la riqueza; las interferencias que se anteponen a estos logros son vistas como atentatorias al bienestar personal y por lo tanto, son origen de una conducta agresiva, de una conducta desviada" (Cano, 1980: 24).

Como podemos apreciar, la corrupción es una forma de violencia, es una forma de imponer los intereses individuales por encima de los del grupo, es la manera de obtener o mantener una hegemonía sobre los demás con los privilegios y beneficios particulares que ello nos reporta.

Si realmente pretendemos modificar los patrones de conducta desviados existentes en nuestro país, entonces debemos admitir que es necesario inducir en los mexicanos, desde sus primeros años, valores tales como la cooperación; la ética; el trabajo en grupo; el amor a la familia, a la escuela y a la patria; y el equilibrio sano, razonado y necesario entre los deberes sociales y las necesidades individuales.

Antes de terminar el presente apartado, quiero citar a Sampson:

La ley moral se apoya en la posibilidad de que cada ser humano se desarrolle, en mayor o menor grado, en una dirección o en otra. El individuo podrá buscar cómo ordenar su vida y sus relaciones con los demás, a partir del amor o del poder. Estas dos fuerzas son antiéticas, pero directamente relacionadas una con otra, pues es imposible desarrollarse en ambas direcciones al mismo tiempo. En la medida en que desarrollemos nuestra capacidad de poder, debilitaremos nuestra capacidad de amar; $y$, a la inversa, en la medida en que aumente nuestra capacidad de amar, aumentará nuestra incapacidad para el éxito en la competencia por el poder. En la medida que triunfen las fuerzas del amor sobre la fuerzas del poder, prevalecerá la igualdad entre los hombres: y, a la inversa, en la medida en que las fuerzas del poder dominen a las fuerzas del amor, las relaciones humanas se caracterizarán por la dominación y la servidumbre. Lo primero es bueno y conduce al bienestar humano; lo segundo es malo y lleva al sufrimiento y al conflicto. (Sampson, 1975: 8). 


\section{Administración pública y corrupción}

La administración pública en el plano real, tiene como propósito fundamental inducir la desorganización de la sociedad y lo logra principalmente mediante un proceso de alienación que despoja al individuo de su conciencia colectiva sustituyéndola por patrones de comportamiento individualistas: "Las necesidades políticas de la sociedad se convierten en necesidades y aspiraciones individuales, su satisfacción promueve los negocios y el bienestar general, y la totalidad parece tener el aspecto mismo de la razón" (Marcuse, 1973: 19). Por tanto, el Estado corrupto siempre buscará organizarse para impedir que la sociedad lo haga y también para concretar la preservación de los intereses económicos y políticos que condujeron al grupo hegemónico al poder, sin importar que para ello adopte otras formas de conducta desviada más graves como son el narcotráfico y la industria de los secuestros. En el caso de México el ejemplo más claro lo encontramos en el estado de Morelos con el gobierno de Carrillo Olea.

De todo lo anterior, podemos inferir la importancia del papel que puede desempeñar la administración pública en un verdadero estado demócrático para guiar a la sociedad hacia el desarrollo compartido de todos sus miembros, siempre y cuando cuente con el apoyo de una sociedad organizada. Así sólo bajo la presión civil el Estado se puede convertir en el brazo ejecutor de la voluntad popular y de ahí que sea imposible negar la relación tan estrecha que existe entre sociedad y administración, tal y como lo afirma Guerrero (1980: 272):

La administración pública capitalista también entraña el doble carácter de dirección y de dominio; de administración y de política. Por tanto, acomete a la vez la realización de funciones públicas y ejercicio del poder político. Lo importante, sin embargo, consiste en que la dirección administrativa implica, como armonización y coordinación, la conducción de las actividades económicas de la sociedad en su conjunto que brotan del desarrollo de las fuerzas productivas. La dirección administrativa, como ejercicio de funciones públicas, consiste en la realización de actividades colectivas en las cuales se sustenta la sociedad y, por tanto, el Estado. La administración pública, como dirección administrativa, brota del trabajo cooperativo asociado que se liga directamente al desarrollo económico.

La complejidad de las estructuras sociales y la creciente división del trabajo no le permite al ciudadano común administrar por sí mismo los recursos públicos y por tanto requiere de elegir a un administrador 
mandante, para que pueda ejercer en su nombre la actividad del Estado. De esta manera surgen los funcionarios públicos que en el caso de México, aprovechan la situación para su propio beneficio a costa de los intereses generales. Su arma principal es la formación de un círculo institucional en el que la complicidad y la protección de actividades ilícitas, sofocan cualquier intento para que estas unidades funcionen debidamente. Las estructuras administrativas lejos de permitir que el Estado cumpla con sus fines colectivos, los obstaculiza y corrompe para satisfacer los intereses de un grupo determinado.

Es obvio que para lograr estos fines pervertidos requiere concentrar en sus manos todo el poder político y administrativo, evitando a toda costa que su autoridad se cuestione o se diluya, por lo que en lugar de democratizar al Estado, por el contrario se ejerce de manera absoluta el poder y evita la injerencia de la sociedad en las funciones que son propias, no le conviene que se instrumente ningún tipo de control pues ello iría en menoscabo de sus intereses específicos. La inoperancia del Estado, inducida por el sistema político mexicano en sus estructuras administrativas, exacerbada por una falta de organización social que le exija el buen cumplimiento de sus funciones en nuestro país, básicamente se refleja en las áreas de la administración pública que a continuación se explican.

\section{Planeación}

El gran problema de la improvisación administrativa se refleja claramente en la deficiente elaboración de un plan rector del desarrollo económico y social, cuyo resultado es que las necesidades reales de toda la sociedad sólo sean tomadas en cuenta, en la medida que se asemejen a los intereses del grupo en el poder, pero el verdadero sentir sobre esas necesidades y su consecuente orden de prelación, están subordinados a intereses particulares del grupo.

Cada sexenio el gobierno federal por tanto, registra una política propia y muchas veces divergente con la del régimen que lo antecede, dejando obras inconclusas, programas parcialmente cumplidos, objetivos inalcanzados, y en general incoherencia entre promesas de campaña y hechos de gobierno. Y no podría ser de otra forma mientras los objetivos, estrategias y acciones del plan no evalúen el efecto y alcance de las acciones del gobierno que los antecedió, ni sean fruto de un verdadero y democrático proceso de consulta popular a largo plazo. 
Son incuantificables los costos sociales y económicos que resultan por una parte de esta falta de coordinación entre el gobierno saliente y el entrante; y por otra debido a la carencia de programas de acción a largo plazo que realmente solucionen los problemas prioritarios del desarrollo. Esta facultad discrecional se le atribuye al Ejecutivo federal, de acuerdo con lo dispuesto en el artículo 26 constitucional, que en su tercer párrafo dice:

La ley facultará al Ejecutivo para que establezca los procedimientos de participación y consulta popular en el sistema nacional de planeación democrática y los criterios para la formulación, instrumentación, control y evaluación del plan y los programas de desarrollo... (Constitución Política, 1996: 24).

Parece pues, demasiado complejo dar cumplimiento a este precepto que a la letra ordena: "El Estado organizará un sistema de planeación democrática del desarrollo nacional que imprima solidez, dinamismo, permanencia, y equidad al crecimiento de la economía para la independencia y la democratización política, social y cultural de la nación", mientras no exista un organismo como el que se propone en esta investigación o en su defecto se diseñe otra forma de participación social para que realmente todos los sectores definan el modelo de país al que debemos aspirar los mexicanos a largo plazo, independientemente del grupo o grupos que detenten el poder del Estado.

Por supuesto que no se trata de que la sociedad sustituya la acción administrativa del Estado en materia de planeación económica y social, como ya se ha afirmado, sino únicamente de apoyar al Estado dándole a conocer con precisión las necesidades que deben satisfacerse con mayor urgencia, a fin de evitar el dispendio de recursos en la realización de obras o prestación de servicios que resultan superfluos y posteriormente, informándole del efecto exacto que producen al llegar al usuario, que es la sociedad toda.

Volvemos a la cuestión de transformar en realidades la voluntad popular que se plasma en nuestra carta constitucional y ello sólo es posible con hechos no con buenos propósitos o palabras. Todo plan se debe formular en orden ascendente, partiendo de la estructura misma de la sociedad a la que sirve y sobretodo, tomando en cuenta estrictamente la atribución que le confiere al Estado el artículo 25 constitucional: 
Corresponde al Estado la rectoría del desarrollo nacional para garantizar que éste sea integral que fortalezca la soberanía de la nación, y su régimen democrático y que, mediante el crecimiento económico y el empleo y una más justa distribución del ingreso, permita el pleno ejercicio de la libertad y la dignidad de los individuos, grupos y clases sociales, cuya seguridad protege esta constitución (Constitución Política, 1996: 22).

La planeación como instrumento de desarrollo debe cumplir al menos con las siguientes funciones: identificar los objetivos generales con la participación equitativa de todos los sectores sociales, cuantificarlos y ponderarlos de polo a polo, establecer preventivamente los mecanismos de participación social en el proceso de evaluación y control, diseñar las alternativas viables para llevarlos a cabo, hacer compatibles las acciones con los recursos disponibles en orden de prioridad, y en general formular los programas sectoriales y los proyectos específicos con la participación del organismo de apoyo a las acciones de gobierno, pautándolos en el tiempo a largo plazocon carácter de obligatoriedad.

La honestidad indudablemente comienza reconociendo la legitimidad de los propósitos plasmados en nuestra Constitución Política y por ello toda la acción de Estado debe encaminarse a cumplir con ellos realmente.

\section{Improvisación laboral}

Otro de los grandes problemas de la administración pública en México ha sido la falta de profesionalización de sus recursos humanos, el empirismo exagerado, el proceso de deterioro que ha sufrido su conocimiento teórico como consecuencia de una actitud de menosprecio hacia la importancia de su papel para alcanzar realmente los objetivos de desarrollo; y es que no podía ser de otra manera, en tanto se vea al aparato gubernamental como un botín político que le permite al grupo hegemónico reclutar entre su membresía a los nuevos funcionarios que habrán de arrasar con programas, políticas, y sobretodo a los recursos humanos que administran y que se consideran usurpadores de los cargos que por derecho le corresponden a su familia, compadres y amigos. Simplemente el cargo público es utilizado para servirse de él personalmente o través de sus amigos, los objetivos institucionales son relegados a un segundo plano.

Es precisamente esta devastación sexenal la que propicia que no se haya podido consolidar una plantilla de servidores públicos que 
conjuguen experiencia con capacidad, Roethlisberegerer afirma: “... teoría sin práctica constituye especulación inútil, y práctica sin teoría es intransmisible"(Roethlisberegerer, 1965: 47). Efectivamente jamás se podrá contar con cuadros administrativos eficaces y eficientes sin una estabilidad que conjugue la experiencia con la formación profesional, por eso aunque un servidor público se esmere en el buen cumplimiento de sus actividades laborales el desenlace será siempre el mismo. A lo más que puede aspirar un funcionario público es a permanecer en su cargo durante seis años, no importando el cumplimiento de sus funciones sino sus relaciones, que son en última instancia las que determinan su permanencia dentro de esa estructura. Esta manera de ver a la administración pública es una forma de corrupción tolerada y promovida por el mismo sistema.

Los administradores públicos no pueden ni deben improvisarse, es cierto que la complejidad de la división del trabajo y la creciente especialización, obliga a las organizaciones a integrarse con equipos multidisciplinarios, pero la función generalizadora y la coherencia que debe existir entre política y administración debe ser campo del dominio de verdaderos especialistas en este campo.

No se debe olvidar la importancia del conocimiento teórico serio y objetivo pues:

El administrador que no tiene una base científica, se asemeja a un médico que está alejado de los conocimientos de anatomía y fisiología; podrá dentro de ciertos límites, ser un practicante más sagaz y hábil que un profesor académico, más tendrá que pagar algún día el precio de su estancamiento. Hasta el más completo de los artesanos, más temprano o más tarde, habrá de inclinarse ante los principios teóricos, pues en el momento mismo que empuña sus herramientas, la teoría estará descubriendo y eliminando dificultades y complicaciones y volviendo a los procesos más simples y económicos (Warwyck, 1943: 15).

Es indubitable e indiscutible el papel protagónico que juega el recurso humano en la búsqueda de los objetivos propuestos por la sociedad en su seno, especialmente cuando se trata del brazo ejecutor de las políticas de Estado que es la administración pública, por eso su formación, capacitación e investigación son asuntos de gran peso tratándose de la materialización de los objetivos generales de desarrollo. Este proceso sólo podrá alcanzarse a través de una verdadera modernización administrativa, entendida como la evolución que experimenta una sociedad como la nuestra con sistemas de reclutamiento arbitrarios y anticuados, hasta convertirla en una 
estructura lógica y racional integrada por servidores públicos con una amplia trayectoria y formación en sus diversas especialidades, que además cuente con salarios adecuados a sus aptitudes y sobretodo con un sistema civil de carrera que lo invite a mejorar su trabajo diario y a superar sus conocimientos.

Desde luego que un servidor público que incumple sus funciones es un funcionario corrupto, por ello una política de selección, reclutamiento y ascensos adecuada, debe contemplar también la posibilidad de eliminar a aquellos elementos que incumplan sus actividades y castigar con rigor a aquellos otros que incurran en prácticas ilícitas para satisfacer sus intereses individuales. De ahí que sea necesario instrumentar periódicamente evaluaciones individuales a todos los servidores públicos a fin de garantizar la calidad en su desempeño.

\section{Formación de los administradores}

Es obvio que los altos puestos de la jerarquía política y administrativa no requieren, al menos formalmente de alguna formación académica en específico. Sin embargo la tendencia de la administración pública es cederle un sitio privilegiado a los colegas del grupo que detenta el poder; sin llegar a comprender que la complejidad de los problemas políticos, económicos y sociales imposibilita a cualquier individuo a tomar decisiones de trascendencia nacional, sin contar con un punto de vista multidisciplinario que evite la dispersión teórica y los enfoques parciales para la solución de los problemas.

Las estrategias y alternativas de acción del Estado para alcanzar los objetivos generales deben emanar del intercambio de conocimientos y puntos de vista de un grupo multidisciplinario, que aporte soluciones integrales que verdaderamente ataquen las causas de los problemas y no sólo sus efectos.

Particularmente en el terreno de los hechos sociales la multicausalidad de los fenómenos es una característica fundamental que los distingue de la fenomenología de las ciencias exactas, por tanto si se utiliza el punto de vista de un solo gremio, seguramente el análisis y propuestas de solución de los problemas serán parciales.

Por otra parte, también es indispensable que aunque los servidores públicos posean conocimientos específicos en alguna materia, por lo menos asistan a cursos semestrales obligatorios de formación en 
materias genéricas dentro de las cuales debiera contemplarse un código de ética, la ley federal de responsabilidades y la vocación de servicio público como prioritarias, además también sería necesario que cumplieran obligatoriamente cada seis meses, con alguna labor de servicio social que los acercara a su comunidad. Humanizar la tarea del burócrata es una tarea fundamental en el programa de combate a la corrupción, pues en la medida en que el empleado público tome conciencia de que es él quien está al servicio del ciudadano y no el ciudadano al suyo, la superposición de los intereses propios a los generales se hará más complicado.

De esta manera, democratizar el procedimiento de selección y reclutamiento de personal, obedeciendo a criterios transparentes, imparciales y basados exclusivamente en la capacidad y actitudes de los individuos, se constituye en un aspecto toral de una sociedad que verdaderamente busca la renovación moral de sus estructuras.

\section{Capacitación}

La dinámica permanente de una sociedad en constante cambio propicia que exista una necesidad recíproca en la estructuras que se encargan de prestarle servicios públicos, de adaptarse a sus necesidades específicas que evolucionan y modifican sus tendencias de acuerdo con el comportamiento de parámetros de orden económico y político. En cambio, en el caso de México este proceso es revertido, la administración pública se considera a sí misma el centro sobre el cual deben girar las necesidades colectivas, según esta filosofía es la sociedad la que debe responder a los cambios en la política económica y social que se imponen sexenalmente.

De ahí que no considere necesario ajustar las estructuras a su entorno y mucho menos preparar al recurso humano, que constituye el elemento básico de toda organización hacia la total satisfacción de las necesidades cambiantes de la colectividad.

Es cierto que existen organismos que se dedican a instrumentar programas de capacitación dentro del Estado en general, pero estas actividades son prácticamente voluntarias, limitadas a grupos pequeños, condicionadas a la voluntad de los jefes y por tanto de alcance muy limitado. La capacitación del servidor público en los niveles de mandos medios es considerada como una pérdida de tiempo, porque de acuerdo con la tradición autoritaria de la burocracia 
mexicana se debe permanecer en las oficinas el mayor tiempo posible aunque no se haga absolutamente nada, el cumplimiento del horario se convierte en el fin último del burócrata para evitar ser cesado.

Debe considerarse el aprendizaje como una serie de cambios operados en la conducta del individuo, como resultado de la incorporación de esquemas inducidos de comportamiento y a las experiencias acumuladas en el pasado. Los cambios reales de conducta se manifestarán cuando el servidor público acepte la necesidad de modificar sus capacidades y conducta a través de los siguientes satisfactores:

- Seguridad: debe tener la sensación de que el hecho de aprender para mejorar le permitirá conservar su empleo.

- Pertenencia: debe identificar sus metas particulares con las del órgano e institución en la que presta sus servicios.

- Propósitos: debe estar convencido de la necesidad para modificar su conducta y así estar en posibilidad de conservar su cargo o ascender dentro de la estructura jerárquica

- Respeto y dignidad: debe recibir un trato humano por parte de sus superiores para proyectarlo hacia aquellos que sirve, en términos de igualdad.

- Vocación de servicio: debe tener conciencia plena de su status de servidor público.

Si un funcionario público encuentra en su encargo la seguridad que se deriva de la satisfacción de sus necesidades básicas de forma decorosa, a través de un ingreso justo, acorde con sus funciones y con esmero en el cumplimiento de los objetivos organizacionales, la posibilidad de incurrir en conductas desviadas será menos factible.

El combate a la corrupción debe iniciarse dentro de la célula misma de las organizaciones públicas, la posibilidad de instaurar un sistema de servicio civil de carrera constituye el camino más corto para transformar el aparato burocrático en un verdadero instrumento para alcanzar las aspiraciones sociales de justicia y desarrollo, claro siempre y cuando se establezcan las condiciones necesarias para que este proceso esté respaldado por una gran participación social y una evaluación permanente de la actividad administrativa en el terreno de la realidad. 


\section{Contraloría social}

Recordemos que la generación de los recursos públicos que sostienen al Estado provienen de la sociedad misma, a través de impuestos, derechos y aprovechamientos, por tanto sólo la sociedad tiene derecho a exigir a su gobierno que rinda cuenta del ejercicio de esos recursos. Por ello resulta verdaderamente aberrante que el Estado mismo sea el encargado de fiscalizarse, ya que se constituye en juez y parte, contraviniendo el principio de imparcialidad que debe prevalecer en un Estado justo.

Por eso en México, órganos como la Contaduría Mayor de Hacienda en el caso del Poder Legislativo, la Secretaría de Contraloría y Desarrollo Administrativo en el caso del Poder Ejecutivo y el Consejo de la Judicatura en el Poder Judicial constituyen una verdadera burla a la democracia, puesto que su inoperancia ha quedado de manifiesto desde el momento mismo de su creación. Lejos de constituir verdaderas áreas preventivas, punitivas o de control se constituyen en unidades protectoras y limpiadoras de los actos de corrupción en que incurren los servidores públicos o miembros económicamente prominentes de la sociedad.

En el caso del Poder Judicial la situación es aún más compleja, puesto que es el órgano que por antonomasia tiene a su cargo la impartición de la justicia, pero su dependencia del Poder Ejecutivo anula su capacidad para actuar imparcialmente, favoreciendo siempre a los ricos o poderosos. De ahí que es necesario establecer un sistema de elección directa para la judicatura, desde los cargos de magistrados hasta los de jueces de Distrito. El único compromiso de estos servidores públicos debe ser con la sociedad y no con el grupúsculo que detenta el poder político o económico.

La sociedad civil debe ser la única que solicite la rendición de cuentas a los tres poderes de la unión, puesto que los recursos los genera ella y además puede medir a la perfección los resultados de la acción gubernamental en el plano de la realidad, aunque cada una de estas instancias puede tener un órgano administrativo que lleve a cabo funciones de evaluación que les permita detectar deficiencias internamente e instrumentar las acciones correctivas necesarias. Pero el órgano defensor de los intereses del pueblo debe ser el encargado directo de vigilar la correcta operación del gobierno y para ello será 
necesario constituirse, a costa del poder omnipotente del Estado, en escrutador permanente de la gestión pública.

Quiero finalizar a manera de reflexión con las palabras de Aristóteles, que a continuación reproduzco:

Veamos pues, en cuantos sentidos se puede decir que un hombre es injusto. Se infama con este nombre a la vez al que falta a las leyes, al que es demasiado codicioso, al inicuo. Por consecuencia, es evidente que deba llamarse justo al que obedece a las leyes y al que observa con los demás las reglas de la igualdad. Así lo justo será lo que conforme a la ley y a la igualdad; y lo injusto será lo ilegal y lo desigual (Aristóteles, 1967: 110).

\section{Conclusiones}

Las relaciones de poder estructuradas mediante esquemas altamente competitivos, el abuso del poder político que fomenta la desigualdad y el rencor social, la mutación de los fines éticos del Estado por fines individualistas perversos, la inaplicabilidad de los dogmas constitucionales que emanan de la voluntad popular, el edonismo y egoísmo instintivo del hombre, la ineficiencia e ineficacia administrativa y sobretodo, la ausencia de una participación social real en la instrumentación y ejercicio del poder público, son factores que definen la aparición de la corrupción en los contextos aquí vertidos. La utilización de la superioridad económica manifiesta también en diversos factores políticos, sociales, psicológicos y administrativos, se traduce en el abuso del poder público para favorecer de manera epicúrea y materialista el interés de la fracción hegemónica.

El establecimiento de relaciones de poder sobre bases de desigualdad y despotismo entre Estado y sociedad, acarrea consigo la perversión de los fines legítimos de toda comunidad organizada políticamente, mismos que idealmente se debieran relacionar con principios éticos de libertad, igualdad y justicia popular. El resultado de esta mutación es el imperio de la corrupción.

Así es como este fenómeno se transforma en expresión pura de un complejo sincretismo que a partir de esta desigualdad y de la confrontación de los intereses particulares de cada individuo con los de la comunidad toda, se manifiesta como un hecho persistente en todos los niveles de interacción del hombre con su entorno. La concatenación de estas causales de la corrupción, a manera de eslabones de una cadena, arroja un hecho objetivo: la necesidad de organización política de la sociedad, a través de una institución totalmente civil, para 
equilibrar su fuerza con la de un desmedido poder gubernamental, que utiliza los privilegios que de su uso se derivan para imponer intereses de un grupo minoritario al resto de sus congéneres.

\section{Bibliografía}

Aristóteles (1961), Moral a Nicomaco. Libro quinto, Lima, Perú: Editorial Universo.

Aristóteles (1997), Política, Madrid, España: Editorial Alianza.

Cano Gordon, Carmen, et al. (1980) La dinámica de la violencia en México, México, D.F: UNAM.

Coser, L (1961), Las funciones del conflicto social, México, D.F.: Fondo de Cultura Económica.

Chinoy, Ely. (1968), La sociedad, México, D.F.: Fondo de Cultura Económica.

Delhumeau, A. et al. (1970), México realidad política de sus partidos. México, D.F.: Editorial Olimpa.

Guerrero, Omar (1980), La administración pública del Estado capitalista, México, D.F.: Ed.itorial Instituto Nacional de Administración Pública.

Jones, Ernest. (1969), Sigmund Freud: Life and Work. vol. 1. Londres, New Home vol 1

Lenin, V. (1981), El Estado y la revolución, México, D.F: Ediciones Populares.

López Chavarría, José Luis (1992), Constitución Política comentada México, D.F.: UNAM.

Marcuse, Herbert (1973), El hombre unidimensional, México, D.F.: Editorial Joaquín Mortiz.

México, Constitución, (1996) Constitución Política de los Estados Unidos Mexicanos. México

D.F.: Editorial Pórrua

Mills, C. (1969), La élite del poder México, D.F.: Fondo de Cultura Económica.

Moliner, María. (1988), Diccionario de uso del español, Madrid, España: Editorial Gredos.

Rodríguez Lozano Amador et al. (1992), Constitución Política Comentada, México D.F.: Editorial DDF-UNAM.

Roethlisberger, F.J. (1965), Managment and morale, California U.S.A.: Ed. New. World.

Rousseau, Juan J.(1979), El contrato social, México D.F.: Editorial Porrúa.

Sampson, R.V. (1975), Igualdad y poder, México, D.F.: Fondo de Cultura Económica.

Sorokyn, Pitrim A. (1967), Society, culture and personality, New York: Harper and bros.

Warwick, L. (1943), The elements of administration, Londres: Harper and biothem.

Xirau, Ramón. (1995), Introducción a la historia de la filosofía México, D.F.: UNAM. 